\title{
Extrahepatic cancer risk after liver transplantation for hepatocellular carcinoma: incidence, risk and prevention
}

\author{
Claire M. Vajdic ${ }^{1}$, Marina T. van Leeuwen ${ }^{1}$, Geoffrey W. McCaughan ${ }^{2}$ \\ ${ }^{1}$ Centre for Big Data Research in Health, University of New South Wales, Sydney 2052, Australia. \\ ${ }^{2}$ Centenary Research Institute, Australian National Liver Transplant Unit, Royal Prince Alfred Hospital, University of Sydney, \\ Sydney 2006, Australia.
}

Correspondence to: Prof. Claire M. Vajdic, Centre for Big Data Research in Health, University of New South Wales, Level 2 AGSM Building, Sydney 2052, Australia. E-mail: claire.vajdic@unsw.edu.au

How to cite this article: Vajdic CM, van Leeuwen MT, McCaughan GW. Extrahepatic cancer risk after liver transplantation for hepatocellular carcinoma: incidence, risk and prevention. Hepatoma Res 2021;7:34. https://dx.doi.org/10.20517/23945079.2020 .159

Received:14 Dec 2020 First Decision: 1 Mar 2021 Revised: 8 Mar 2021 Accepted: 2 Apr 2021 Published: 8 May 2021

Academic Editors: Guang-Wen Cao, James Fung Copy Editor: Yue-Yue Zhang Production Editor: Yue-Yue Zhang

\begin{abstract}
This article synthesises the current evidence on the risk of de novo extrahepatic cancer in people living with a liver transplant after hepatocellular carcinoma, the risk factors for cancer, and the recommended approaches to cancer prevention and surveillance. People living with a transplanted liver have an elevated risk of cancer and cancer death, and the indication for transplantation does not markedly alter the cancer risk. The excess risk of cancer is double that of the age- and sex-matched general population. Virus-related cancers, especially non-Hodgkin lymphoma, Kaposi sarcoma, Merkel cell carcinoma, oral, and anogenital cancers occur at increased risk, as do cancers causally associated with high prior sun exposure, smoking and excessive alcohol consumption, including skin, oesophageal, larynx, lung, kidney, and bladder cancer. The risk of incident breast and prostate cancer is not increased. Cancer-related deaths largely mirror that for cancer incidence, and extend to include the more common malignancies such as breast, colorectal, prostate cancer and non-melanoma skin cancer. As medical immunosuppression is the principal risk factor for cancer, the regimen should be reviewed on a regular basis to achieve immunosuppression minimisation. An individual, risk-based approach to cancer screening according to test characteristics and personal and family cancer history, medical history, lifestyle factors, and life expectancy is recommended. Multicomponent interventions may achieve the best results in supporting the adoption and maintenance of cancer risk-reducing behaviours. Regular, empowering patient counselling and education is a cornerstone for the care of people living with a liver transplant.
\end{abstract}


Keywords: Cancer, risk, prevention, screening, surveillance, cohort

\section{INTRODUCTION}

Advances in surgical techniques, patient selection and immunosuppressive regimens have improved survival outcomes for liver transplant recipients. However, people living with a transplanted liver continue to have an excess risk of cancer and death from cancer. This excess cancer risk is predominantly attributed to exposure to medical immunosuppression ${ }^{[1]}$, but other known carcinogenic exposures before and after transplantation such as infection with an oncogenic virus, smoking, heavy alcohol consumption and sun exposure, are also contributing factors ${ }^{[2]}$. Recipients of liver transplants have a lower risk of cancer compared to recipients of cardiothoracic organs and kidneys, due to generally lower overall doses of immunosuppression ${ }^{[3-5]}$.

Liver transplantation is an effective therapeutic option for select patients diagnosed with hepatocellular carcinoma (HCC) $)^{[6]}$. Improved patient/tumour selection algorithms have resulted in similar survival outcomes for people living with a transplanted liver with and without a history of $\mathrm{HCC}^{[6-8]}$. HCC is a relatively common indication (40\%-50\%) for transplantation in countries with a higher incidence of HCC and is an increasing indication for liver transplantation globally. In the United States in 2018, HCC was the primary indication for $10.5 \%$ of waitlist candidates, and the third most common indication for transplantation ${ }^{[9]}$. Importantly in terms of cancer risk after transplantation, the proportion of older candidates (age $\geq 65$ years) has also increased over time; such individuals comprised $24 \%$ of the United States waitlist candidates in $2018^{[0]}$.

This review presents the current evidence on the risk of de novo extrahepatic cancer in people living with a liver transplant after HCC, the risk factors for cancer, and the recommended approaches to cancer prevention and surveillance. There is limited reliable evidence about cancer risk after liver transplantation for HCC. However, international population-based evidence indicates the indication for transplantation does not markedly alter the cancer risk profile, and thus much can be inferred from such studies of all liver transplant recipients as well as other solid organ transplant recipients. This article synthesises populationbased evidence on the epidemiology of cancer after liver transplantation for any indication and, where it exists, transplantation for HCC.

\section{CANCER RISK}

Historically, most high-quality evidence on the cancer incidence and mortality profile of people living with a liver transplant has been generated from Western populations, due to their long-established population cancer registries and record linkage infrastructure. Such infrastructure is needed to perform populationbased studies, defined as studies of all transplant recipients that capture all incident cancers, regardless of the setting in which they were diagnosed. These studies are considered the highest quality of observational evidence. However, the findings may not be entirely generalisable to other populations with different characteristics, particularly if they vary with respect to the prevalence of infection with oncogenic viruses, especially hepatitis B (HBV), hepatitis C (HCV), human immunodeficiency virus (HIV), human papillomavirus (HPV) and Epstein-Barr virus $(\mathrm{EBV})^{[10]}$, and the predominant indications for transplantation ${ }^{[11]}$. Furthermore, most of these studies have reported on all liver transplant recipients, not just those transplanted for HCC, and in Western populations the proportion of recipients with a history of HCC is comparatively small $(\sim 10 \%)$ compared to many Eastern populations $(40 \%-50 \%)^{[3,12-14]}$. 
The population-based evidence from Western, predominantly Caucasian populations shows a 2 - to 3 -fold excess risk of cancer in adults living with a liver transplant [Table 1 $]^{[3,12,13,15-17]}$. These national studies have typically shown an excess cancer risk regardless of the indication for transplantation, with the highest risk usually observed for people living with a liver transplant after alcoholic cirrhosis and primary sclerosing cholangitis ${ }^{[14]}$. Evidence also shows a high short-term cancer risk, driven mostly by the occurrence of nonHodgkin lymphoma in the early post-transplant period ${ }^{[12]}$. However, cancer risk is not confined to the early post-transplant period, and continues to increase with increasing time from transplantation and exposure to immunosuppression. Some ${ }^{[14]}$, but not all ${ }^{[1,18]}$, studies that have examined cancer risk by year of liver transplantation suggest a lower risk of cancer in people transplanted in more recent eras. This is likely to be associated with transplant clinical practice recommendations to minimise the overall dose of immunosuppression.

Non-Hodgkin lymphoma is the most common non-skin cancer in people living with a liver transplant. In solid organ transplant recipients, high short-term risk is associated with more intense immunosuppression and lack of immunological control of EBV infection in the early period ${ }^{[5,19]}$. However, an excess risk is also observed many years after transplantation. In Western populations, the most common solid malignancy after liver transplantation is skin cancer, and an excess skin cancer risk is observed throughout the followup period. This includes melanoma, keratinocyte cancer [basal cell carcinoma (BCC) and squamous cell carcinoma (SCC)] and Merkel cell carcinoma, although these malignancies are less common among recipients of liver transplants than among those of cardiothoracic transplants ${ }^{[3]}$.

Virus-related cancers, especially non-Hodgkin lymphoma, Kaposi sarcoma, Merkel cell carcinoma, oral (head and neck), cervical and other anogenital cancers occur at increased risk in liver transplant recipients ${ }^{[2]}$, as do cancers causally associated with smoking and excessive alcohol consumption, including oesophageal, larynx, lung, kidney, and bladder cancer. The risk of breast and prostate cancer is not increased in people living with a liver transplant. The increased risk of colorectal cancer observed in liver transplant cohorts is confined to those receiving a liver transplant with a history of primary sclerosing cholangitis with and without inflammatory bowel disease ${ }^{[20-22]}$. Evidence is emerging from very large-scale cancer registry linkage studies of solid organ transplant recipients that they are also at excess risk of numerous rare cancers (incidence $<6$ per 100,000 person-years), including cancers of the eye and adnexa, salivary gland, nasal cavity and anus, and neuroendocrine tumours and specific subtypes of sarcoma ${ }^{[23]}$. The risk of several, but not all, of these cancers was shown to increase with increasing time since transplantation.

More recently, evidence on the risk of cancer in people living with a liver transplant has been published for Taiwanese and Korean populations. Although the source of transplant recipients and cancer outcomes in these studies is health insurance databases, and is thus not population-based, this evidence also demonstrates a moderate excess risk of cancer ${ }^{[24-26]}$. A range of viral- and non-viral cancers were observed to occur at rates higher than background rates, including skin cancer in some cohorts.

The whole-of-population evidence regarding cancer risk after liver transplantation for HCC is less extensive, with few studies having sufficient power to generate reliable estimates for individual cancers [Table 2]. The largest study showed a 1.6-fold excess risk of any cancer, and a similar site-specific cancer risk profile to that observed for all people living with a transplanted liver ${ }^{[14]}$. Non-population based evidence from South Korean patients transplanted for HCC has also generated a similar cancer profile to that described above, as well as an excess risk of leukemia, myeloma, and thyroid cancer ${ }^{[27]}$. Interestingly, this study found a substantially higher short-compared to long-term risk of cancer, with most cancers diagnosed within the first 12 months of transplantation. 
Table 1. Risk of any cancer in national population-based cohort studies of people living with a liver transplant, irrespective of indication

\begin{tabular}{|c|c|c|c|c|}
\hline Country & Period & Cancers & $\begin{array}{l}\text { Population } \\
\text { subgroup }\end{array}$ & $\begin{array}{l}\text { Standardised incidence ratio } \\
(95 \% \mathrm{Cl})\end{array}$ \\
\hline Netherlands ${ }^{[13]}$ & 1979-1996 & $\begin{array}{l}\text { All, including SCC and } \\
\mathrm{BCC}\end{array}$ & All & $4.3(2.4-7.1)$ \\
\hline \multirow[t]{3}{*}{ Canada $^{[15]}$} & \multirow[t]{3}{*}{ 1983-1998 } & \multirow{3}{*}{$\begin{array}{l}\text { All, excluding SCC and } \\
\text { BCC }\end{array}$} & Age $35-<50^{*}$ & $3.9(2.7-5.4)^{\#}$ \\
\hline & & & Age $50-<60^{\star}$ & $1.4(0.9-2.1)^{\#}$ \\
\hline & & & Age $60^{*}$ & $1.6(1.1-2.4)^{\#}$ \\
\hline \multirow[t]{2}{*}{ Finland $^{[12]}$} & \multirow[t]{2}{*}{$1982-2005$} & \multirow{2}{*}{$\begin{array}{l}\text { All, including SCC and } \\
\text { BCC }\end{array}$} & Age 17-39 years & $5.77(1.87-13.5)$ \\
\hline & & & Age 40 years & $2.27(1.55-3.20)$ \\
\hline Australia $^{[3]}$ & $1984-2006$ & $\begin{array}{l}\text { All, excluding SCC and } \\
\text { BCC }\end{array}$ & Adults & $2.29(1.94-2.69)$ \\
\hline \multirow[t]{2}{*}{ Sweden ${ }^{[17]}$} & \multirow[t]{2}{*}{$1970-2008$} & All, including SCC & All ${ }^{\star}$ & $3.4(2.9-4.0)$ \\
\hline & & All, excluding SCC & All* & $2.3(1.9-2.8)$ \\
\hline United Kingdom $^{[16]}$ & $1980-2007$ & $\begin{array}{l}\text { All, excluding SCC and } \\
\text { BCC }\end{array}$ & All & $2.2(2.0-2.4)$ \\
\hline \multirow[t]{2}{*}{$\begin{array}{l}\text { Nordic region (Finland, Sweden, } \\
\text { Norway, Denmark) }\end{array}$} & \multirow[t]{2}{*}{$1982-2013$} & $\begin{array}{l}\text { All, including SCC and } \\
\text { BCC }\end{array}$ & All & $2.22(2.02-2.43)$ \\
\hline & & $\begin{array}{l}\text { All, excluding SCC and } \\
\text { BCC }\end{array}$ & All & $1.69(1.51-1.88)$ \\
\hline France $^{[11]}$ & 1993-2012 & $\begin{array}{l}\text { All, excluding SCC and } \\
\text { BCC }\end{array}$ & All & $2.20(2.08-2.33)$ \\
\hline Italy ${ }^{[18]}$ & $1985-2014$ & $\begin{array}{l}\text { All, excluding SCC and } \\
\text { BCC }\end{array}$ & Adults only & $1.8(1.6-2.0)$ \\
\hline
\end{tabular}

*Excluded people with a history of cancer before transplantation. " Excluded incident HCC after transplantation. BCC: Basal cell carcinoma; HCC: hepatocellular carcinoma; SCC: squamous cell carcinoma.

\section{CUMULATIVE CANCER INCIDENCE}

Large-scale data from the United States Scientific Registry of Transplant Recipients (SRTR) database, based on physician-reported cancer diagnoses, estimate the cumulative incidence of de novo extrahepatic cancer after liver transplantation for any indication to be $1.3 \%$ (95\%CI: $1.3-1.4)$ at 1 year post-transplantation, increasing to $6.2 \%(6.0-6.4)$ at 5 years, $11.5 \%(11.3-11.8)$ at 10 years, $15.8 \%(15.5-16.2)$ at 15 years, $18.8 \%$ $(18.4-19.3)$ at 20 years and $20.5 \%(19.9-21.1)$ at 25 years $^{[28]}$. Estimates from German single-institution studies vary; $12.9 \%$ at 10 years and $23 \%$ at 25 years in one study ${ }^{[29]}$, and $10 \%$ at 5 years, $26.4 \%$ at 10 years and $34.7 \%$ at 15 years in another ${ }^{[30]}$.

\section{CANCER MORTALITY RISK}

Thirteen percent of deaths overall ${ }^{[31]}$ and up to $20 \%$ of long-term deaths in people living with a liver transplant ${ }^{[32]}$, are attributed to cancer. Population-based evidence indicates a 2 -fold excess risk of death from cancer in Western populations transplanted predominantly for indications other than $\mathrm{HCC}^{[1,33,34]}$. In one Canadian study of solid organ transplant recipients, the highest risk of cancer mortality was observed in recipients who underwent transplantation for cancer $^{[34]}$. The cancer mortality profile largely mirrors that for cancer incidence, and extends to include non-melanoma skin cancer ${ }^{[18,33]}$, as well as breast, colorectal and prostate cancer ${ }^{[1,3,35,36]}$.

The excess risk of cancer death after liver transplantation is related to the increased incidence of cancer, and may also reflect the more advanced stages of cancer at diagnosis and likely more biologically aggressive cancers in the context of immunosuppression ${ }^{[3,3,37,38]}$. Furthermore, it appears that solid organ transplant recipients may receive less aggressive cancer therapy, either on account of their frailty, or to minimise the 
Table 2. Risk of any cancer and specific cancer in national population-based cohort studies of people living with a liver transplant after HCC or liver tumour

\begin{tabular}{|c|c|c|c|c|}
\hline Country & Period & $\begin{array}{l}\text { Indication (sample } \\
\text { size) }\end{array}$ & Cancers & $\begin{array}{l}\text { Standardised incidence ratio } \\
(95 \% \mathrm{CI})\end{array}$ \\
\hline Finland $^{[12]}$ & $1982-2005$ & Liver tumour $(n=46)$ & $\begin{array}{l}\text { All, including SCC and } \\
\mathrm{BCC}\end{array}$ & $0.79(0.19-3.40)$ \\
\hline Australia $^{[3]}$ & 1984-2006 & $\begin{array}{l}\text { Hepatobiliary tumour }(n= \\
\text { 93) }\end{array}$ & $\begin{array}{l}\text { All, excluding SCC and } \\
\text { BCC }\end{array}$ & $0.94(0.11-3.39)$ \\
\hline \multirow[t]{11}{*}{$\begin{array}{l}\text { Nordic region (Finland, Sweden, } \\
\text { Norway, Denmark) }\end{array}$} & 1982-2013 & $\operatorname{HCC}(n=535)$ & $\begin{array}{l}\text { All, including SCC and } \\
\mathrm{BCC}\end{array}$ & $1.64(1.16-2.25)$ \\
\hline & & & $\begin{array}{l}\text { All, excluding SCC and } \\
\mathrm{BCC}\end{array}$ & $1.26(0.84-1.82)$ \\
\hline & & & $\mathrm{SCC}$ and $\mathrm{BCC}$ & $10.7(5.14-19.7)$ \\
\hline & & & Cutaneous melanoma & $3.83(1.04-9.80)$ \\
\hline & & & $\begin{array}{l}\text { Non-Hodgkin } \\
\text { lymphoma }\end{array}$ & $2.84(0.34-10.3)$ \\
\hline & & & Colorectal & $0.83(0.09-2.98)$ \\
\hline & & & Pancreas & $2.03(0.05-11.3)$ \\
\hline & & & Kidney & $1.83(0.05-10.19)$ \\
\hline & & & Lung & $2.79(0.90-6.50)$ \\
\hline & & & Breast & $0.65(0.02-3.63)$ \\
\hline & & & Prostate & $0.41(0.09-1.21)$ \\
\hline
\end{tabular}

BCC: Basal cell carcinoma; HCC: hepatocellular carcinoma; SCC: squamous cell carcinoma.

risk of graft rejection. In a United States study, transplant recipients with cancer were less likely to undergo surgery and radiotherapy compared with non-transplant recipients with cancer ${ }^{[3]}$.

An analysis of United States SRTR data on adults transplanted for HCC showed that malignancy was more prevalent as a cause of late- (> 5 years) compared to early-mortality (1st year) $)^{[39]}$.

\section{RISK FACTORS FOR ANY CANCER}

Another analysis of the United States SRTR database, which includes longitudinal measures of immunosuppressive therapy up to 12 months after liver transplantation, found risk of any cancer increased with older age at transplantation, male sex, white race, multiorgan transplant, history of any cancer, and alcoholic liver disease, autoimmune disease, non-alcoholic steatohepatitis and primary sclerosing cholangitis compared with hepatitis $\mathrm{C}$ viral infection ${ }^{[28]}$. This study found no association between cancer risk and type of immunosuppression. Another interrogation of the United States SRTR data showed an increased cancer risk in those with a history of cutaneous SCC, but not BCC ${ }^{[40]}$.

Most population-based studies do not have data on recipients' smoking or tobacco history. However, singlesite studies, with well characterised liver transplant cohorts, have shown a higher risk of extrahepatic cancer, for current and previous smokers compared to non-smokers ${ }^{[11,42]}$. In addition to smoking, a large-scale single-site study in Germany observed that older age and use of cyclosporine-A compared to tacrolimus therapy increased the risk of de novo cancer ${ }^{[29]}$. In contrast, another single-centre German study that did not have smoking data found increased de novo cancer risk in association with older age, male gender and tacrolimus-based immunosuppression at transplantation ${ }^{[30]}$. In this study, HCC as an indication for transplantation was not associated with cancer risk in multivariable modelling. 
A population-based United Kingdom Transplant Registry study examined all solid organ transplant recipients and found no evidence of an association between risk of cancer and cytomegalovirus infection ${ }^{[43]}$.

\section{RISK FACTORS FOR THE MOST COMMON CANCERS Non-Hodgkin lymphoma}

The incidence of post-transplant lymphoproliferative disorders/non-Hodgkin lymphoma after liver and other solid organ transplantation follows a bimodal pattern ${ }^{[19,44,45]}$. In one population-based study of kidney transplant recipients, early non-Hodgkin lymphoma ( $<2$ years after transplantation) was associated with EBV seronegativity at transplantation and receipt of antibody therapy ${ }^{[19]}$. The association of early nonHodgkin lymphoma with EBV seronegativity at transplantation is a consistent finding and explains the markedly higher risk of early non-Hodgkin lymphoma in paediatric compared to adult transplant recipients ${ }^{[46]}$, in the absence of prophylaxis and monitoring of EBV viral load. Late non-Hodgkin lymphoma ( $\geq 2$ years after transplantation) was associated with older age at transplantation, increasing time since transplantation and current use of calcineurin inhibitors. Another population-based study of liver and cardiothoracic transplant recipients found an increased risk of early- and late-non-Hodgkin lymphoma in association with higher mean daily doses of azathioprine $e^{[5]}$. Azathioprine is not currently recommended in liver transplantation, regardless of indication.

\section{Head and neck cancer}

A multi-centre Italian study identified an association between older age at transplantation, greater time since transplantation, history of heavy smoking and history of alcoholic liver disease and the incidence of head and neck cancer after liver transplantation, with risk markedly increased in those with a history of both smoking and alcoholic liver disease ${ }^{[47]}$.

\section{Keratinocyte skin cancer (BCC and SCC; non-melanoma skin cancer)}

Population-based evidence in solid organ transplant recipients indicates increased risk of keratinocyte cancer in association with older age at transplantation, white compared to black race, longer time since transplantation, history of skin cancer prior to transplantation, occurrence of precancerous skin lesions after transplantation, and male sex ${ }^{[16,48,49]}$. Several of these factors are proxies for high prior sun exposure, information that is not usually available at the population-level. A United Kingdom single-centre study of ethnically diverse organ transplant recipients reported that light skin phototype (Fitzpatrick skin type I-IV), history of sun exposure, older age at transplant and longer time since transplantation increased the risk of keratinocyte cancer ${ }^{[50]}$. A French single-centre study of liver transplant recipients observed a very similar risk profile, and no association with indication for transplantation or immunosuppressive agent ${ }^{[51]}$. A Korean single-centre study reported that risk of skin cancer was associated with older age at transplantation and treatment with more than two immunosuppressive agents; no associations were observed for individual immunosuppressive agents ${ }^{[52]}$.

A recent retrospective study in two French transplant centres found that risk of keratinocyte cancer in liver transplant recipients with a history of SCC, BCC or Bowen's disease was significantly reduced after withdrawal of calcineurin inhibitors ${ }^{[53]}$. Furthermore, a retrospective population-based Irish study of liver transplant recipients observed a significant reduction in keratinocyte risk after conversion of maintenance immunosuppression from calcineurin inhibitors to mTOR inhibitors for clinical indications ${ }^{[54]}$. However, a meta-analysis of studies of non-renal organ transplant recipients found no significant protective effect of mTOR inhibitors on risk of primary or secondary keratinocyte cancer ${ }^{[55]}$. Nevertheless, the complete risk profile must always be considered, as demonstrated by a meta-analysis of individual patient data from randomised trials of kidney transplant recipients that found sirolimus use was associated with a reduced risk of any malignancy and non-melanoma skin cancer, but an increased risk of all-cause death ${ }^{[56]}$. 


\section{Lip cancer}

In an Australian population-based study of liver and cardiothoracic transplant recipients, the risk of lip cancer was associated with older age at transplantation, earlier transplantation era, greater time since transplantation, history of smoking and higher current and mean dose of azathioprine $e^{[4]}$.

\section{RISK FACTORS FOR CANCER-RELATED DEATH}

A study of United States SRTR recipients transplanted for HCC with linked national pharmacy claims data found no relationship between cancer-specific mortality and use of sirolimus in the first 3 months after transplantation ${ }^{[57]}$. This finding mirrored those for all-cause mortality, and is thus at odds with the metaestimate from randomised trials of kidney transplant recipients ${ }^{[56]}$.

\section{TRANSMISSION OF DE NOVO CANCER}

On account of rigorous donor evaluation and inspection of organs prior to transplantation, the risk of transmitting de novo cancer from a liver donor to a recipient is exceedingly low (0.03\%-0.06\%). A recent systematic review of case reports identified a total of 92 confirmed transmitted cancers, the most frequent being lymphomas (33\%), melanomas (9\%) and neuroendocrine tumours (9\% ${ }^{[58]}$. Most (80\%) transmitted cancers were diagnosed within the first year, and $90 \%$ were diagnosed within 2 years.

\section{CANCER PREVENTION AND SURVEILLANCE}

There is consistent evidence that cancers diagnosed in people living with a transplanted organ are at a more advanced stage than those in the general population, and that transplant recipients with cancer have worse outcomes than the general population with cancer. The bulk of this evidence comes from population-based studies of kidney transplant recipients ${ }^{[35,37,38]}$, but there is also evidence from large single-site studies of liver transplant recipient ${ }^{[20]}$. It is therefore critical that cancer prevention and surveillance are built-into the care of people living with a liver transplant, to reduce the risk of cancer and to detect cancers at an early stage of development.

\section{Immunosuppression}

There is uncontested evidence from organ transplant recipients and people living with HIV infection linking immunosuppression and cancer occurrence ${ }^{[1,2]}$. The mechanism is believed to be impaired immune surveillance of neoplastic cells. The risk of cancer in people living with a liver transplant can be reduced by tapering the dose of immunosuppression whilst balancing this risk against the risk of loss of the allograft, renal toxicity and metabolic syndrome. It is therefore recommended that the immunosuppression regimen be reviewed on a regular basis to achieve immunosuppression minimisation. Innovative techniques are being explored to reduce the need for lifelong high-dose immunosuppression, including treatment with natural regulatory $\mathrm{T}$ cells (nTregs ${ }^{[59]}$. In select people living with a transplanted liver for at least 3 years, immunosuppression can be stopped without graft rejection or subclinical alloimmune damage, a state known as "operational tolerance" ${ }^{[60]}$. Operational tolerance is more likely to be achieved in older recipients (> 60 years) and those without autoimmune liver disease, but it is not generally recommended for HCC patients.

The most appropriate immunosuppressive agent(s), and whether immunosuppressive drugs can be directly oncogenic are contentious. Most observational cancer risk factor studies have assessed the immunosuppressive regimen at transplantation and have not taken into account changes over time, and nor have they controlled for the duration of immunosuppression. The few population-based studies with detailed longitudinal data on immunosuppressive agents are inconsistent. 


\section{Infection with oncogenic viruses}

Hepatitis B and tetravalent HPV vaccination are recommended for HPV-negative and paediatric patients, ideally before transplantation. Antiviral drugs for HBV, HCV and HIV infection must be administered as early as possible after diagnosis.

\section{Cancer screening}

An individual, risk-based approach to cancer screening according to patient characteristics including personal and family cancer history, medical history, lifestyle factors, and life expectancy is recommended for people living with a liver transplant. It is also important to consider the screening test characteristics, and to acknowledge that the cancer screening recommendations for the general population have not been extensively tested in people living with a liver transplant.

As there is sufficient evidence of an excess risk of cervical cancer in liver transplant recipients, health professionals are advised to follow the guidelines for another immunosuppressed group, HIV-infected women ${ }^{[61]}$. This means annual cervical cytology after transplantation, and if 3 consecutive cytology results are normal, moving to cytology every three years. Co-testing with cytology and HPV testing is preferred; if the cytology is normal and HPV is negative, then co-testing can be performed every 3 years. The risk of cervical cancer extends for many years after transplantation, necessitating lifelong screening beyond age 65 years. Cervical screening should only be discontinued on the basis of a shared agreement between the physician and patient, taking into account the quality and duration of life. For male and female transplant recipients, an annual anogenital examination is recommended.

Melanomas diagnosed in people living with a transplanted organ are at a more advanced stage than those in the general population, and the survival outcomes are worse ${ }^{[37,62]}$. Physicians should conduct an annual total skin assessment for people at low risk of melanoma or non-melanoma skin cancer, and refer those at high risk for an annual total skin assessment by a dermatologist, preferably experienced in the management of people with immunosuppression. Prophylactic excision of truncal nevi has been advised on the basis of high-quality Swedish data ${ }^{[62]}$, while in an Australian setting, referral to a specialised transplant dermatology clinic resulted in the early detection of melanomas and markedly improved outcomes ${ }^{[63]}$. Similarly, adherence to annual dermatology assessments has been shown to reduce keratinocyte cancer-related morbidity or death ${ }^{[64]}$. People living with a liver transplant should also perform regular skin checks themselves and seek urgent medical opinions if they notice a change. Harwood et al. ${ }^{[50]}$ have generated an algorithmic, evidence-based risk stratification approach to skin cancer screening of an ethnically diverse transplant population that includes skin type, age at transplant and sunburn history; annual surveillance is recommended for the higher risk group, and modifications are necessary after the first SCC or BCC.

The potential value of polygenic risk scores (PRS) in cancer risk stratification is not yet clear. However, both studies that applied a non-transplant PRS for keratinocyte cancer to organ transplant recipients found it predicted time to first keratinocyte cancer post-transplantation ${ }^{[6,66]}$.

As there is no excess risk of breast, bowel or prostate cancer after liver transplantation (other than bowel cancer for those with inflammatory bowel disease), patients should be advised to participate in national screening programmes for these malignancies, where available, according to the guidelines for the general population, or as indicated by their family history. Some argue, however, that given the excess risk of death for these cancers, and the consistent evidence of biological aggressiveness in the context of immunosuppression, transplant recipients should receive more intensive screening, including colonoscopy for all those over 50 years of age ${ }^{[29,36]}$. It may also be advisable to start bowel cancer screening earlier than population-based recommendations for those with a history of alcoholic or viral cirrhosis. 
Given their higher risk of lung cancer, people living with a liver transplant who are former or current smokers may benefit from annual lung cancer screening using low-dose chest computed tomography (CT). Clinical trial evidence in non-transplant populations indicates lower lung cancer mortality in screened individuals than that in unscreened individuals ${ }^{[67,68]}$, although false positives are common and screening is not yet routinely implemented in all settings. A recent small French hospital-based study $(n=147)$ retrospectively examined the efficacy of an intensive cancer screening program for people living with a liver transplant for alcoholic liver disease who actively smoked ${ }^{[6]}$. The screening program consisted of an annual health check, clinical examination by an otorhinolaryngologist, a chest CT scan and an upper digestive endoscopy. Overall, this program did not result in higher rates of curative treatment over a median followup of 10 years, but when a lung cancer diagnosis was made by CT scan compared to symptoms, curative treatment was statistically significantly more likely.

Given the excess risk of oral cancers in people living with a liver transplant, good oral hygiene and annual dental examinations, with a full examination of the oral cavity, are strongly recommended. Annual ear, nose and throat examinations by a head and neck specialist should be performed for current and former smokers and people with a history of alcohol-related liver disease.

Liver transplant recipients in countries with a high background incidence of gastric cancer may benefit from screening with esophagogastroduodenoscopy (EGD) more frequently than recommended for the general population (i.e., every 2 years for people aged 40 years in South Korea $)^{[70]}$.

\section{Lifestyle interventions}

Patient counselling is a cornerstone for the care of people living with a liver transplant. In addition to maintaining their immunosuppressive medications, transplant recipients must be actively supported to stop smoking, including with the assistance of a specialist counsellor, nicotine patches, and/or pharmacological agents.

Transplant recipients must also be counselled and supported to avoid sun exposure and sunburns, and if sun exposure is unavoidable, then they must wear a wide-brimmed hat, full-length clothing and high sun protection factor sunscreen, and the sunscreen must be reapplied regularly. They must also be advised never to use a sunbed or sunlamp to achieve a suntan.

Similarly, advice, encouragement, education and support should be directed towards abstinence from alcohol consumption, maintaining a healthy diet and healthy weight, and pursuing regular physical activity. Patients with excessive alcohol use should be referred to addiction services, where appropriate. Surgical and medical solutions available to the general population to manage obesity are not contraindicated in liver transplant recipients. Individuals at high risk of keratinocyte cancer may benefit from targeted nutritional management, specifically advice and support to maintain a relatively high intake of long-chain omega-3 polyunsaturated fatty acid and -linolenic acid, such as via the consumption of oily fish ${ }^{[71]}$.

Self-efficacy and accountability to the medical team are motivating factors to follow medical advice, and multicomponent interventions including personalised care plans, education, psychosocial support, decision aids and self-monitoring tools may achieve the best results ${ }^{[72]}$. Clinicians should facilitate honest and open discussions with people living with a liver transplant, and their family, regarding lifestyle behaviours that increase, and decrease the risk of cancer. A holistic approach is essential, being mindful of an individual's financial constraints, and other relevant social and cultural factors. Empathy and an exploration of patient attitudes to certain behaviours, including discussing the benefits of those behaviours, may translate to less 
risky behaviours ${ }^{[73]}$. Patients would likely benefit from a coordinated medical approach, with sharing of information, strategies and outcomes with their primary care clinician ${ }^{[7]}$.

\section{Chemoprevention}

A retrospective study in United Kingdom organ transplant recipients with a history of at least one SCC found that low-dose systemic retinoids reduced the incidence of new SCCs ${ }^{[75]}$. Since this study, the evidence has grown, and oral retinoids are recommended for the prophylaxis of keratinocyte cancer and actinic keratoses in organ transplant recipients. Chemoprophylaxis with other agents, including oral nicotinamide and capecitabine, may also be effective at reducing the incidence of melanoma and keratinocyte cancers, although supportive evidence in organ transplant recipients is limited.

\section{CONCLUSION}

Liver transplant recipients have a 2 -fold excess risk of cancer and cancer-related death after transplantation, regardless of the indication for transplantation. HCC is an increasing indication for liver transplantation. The most common incident cancers are those causally associated with oncogenic viruses, and those associated with sun exposure, smoking and alcohol consumption. The cancer mortality profile includes most cancers. Cancer risk can be reduced by minimising the extent of immunosuppression, by performing risk-stratified cancer screening and surveillance, and by giving regular, empowering support and education to recipients so they can adopt and maintain cancer risk-reducing behaviours.

\section{DECLARATIONS}

\section{Authors' contributions}

Made substantial contributions to the conception and content of the report: Vajdic CM, van Leeuwen MT, McCaughan G

Drafting the work or revising it critically for important intellectual content: Vajdic CM, van Leeuwen MT, McCaughan G

Final approval of the version to be published: Vajdic CM, van Leeuwen MT, McCaughan G

\section{Availability of data and materials}

Not applicable.

\section{Financial support and sponsorship}

None.

\section{Conflicts of interest}

All authors declared that there are no conflicts of interest.

\section{Ethical approval and consent to participate}

Not applicable.

\section{Consent for publication}

Not applicable.

\section{Copyright}

(c) The Author(s) 2021. 


\section{REFERENCES}

1. Dantal J, Hourmant M, Cantarovich D, et al. Effect of long-term immunosuppression in kidney-graft recipients on cancer incidence: randomised comparison of two cyclosporin regimens. Lancet 1998;351:623-8. DOI PubMed

2. Grulich AE, van Leeuwen MT, Falster MO, Vajdic CM. Incidence of cancers in people with HIV/AIDS compared with immunosuppressed transplant recipients: a meta-analysis. Lancet 2007;370:59-67. DOI PubMed

3. Na R, Grulich AE, Meagher NS, McCaughan GW, Keogh AM, Vajdic CM. Comparison of de novo cancer incidence in Australian liver, heart and lung transplant recipients. Am J Transplant 2013;13:174-83. DOI PubMed

4. Na R, Laaksonen MA, Grulich AE, et al. High azathioprine dose and lip cancer risk in liver, heart, and lung transplant recipients: a population-based cohort study. J Am Acad Dermatol 2016;74:1144-1152.e6. DOI PubMed

5. Na R, Laaksonen MA, Grulich AE, et al. Iatrogenic immunosuppression and risk of non-Hodgkin lymphoma in solid organ transplantation: a population-based cohort study in Australia. Br J Haematol 2016;174:550-62. DOI PubMed

6. Mehta N, Bhangui P, Yao FY, et al. Liver transplantation for hepatocellular carcinoma. Working Group Report from the ILTS Transplant Oncology Consensus Conference. Transplantation 2020;104:1136-42. DOI PubMed

7. Dageforde LA, Fowler KJ, Chapman WC. Liver transplantation for hepatocellular carcinoma: current update on treatment and allocation. Curr Opin Organ Transplant 2017;22:128-34. DOI PubMed

8. Xu X, Lu D, Ling Q, et al. Liver transplantation for hepatocellular carcinoma beyond the Milan criteria. Gut 2016;65:1035-41. DOI PubMed PMC

9. OPTN/SRTR 2018 Annual Data Report: Liver. Available from https://srtr.transplant.hrsa.gov/annual_reports/2018/Liver.aspx. [Last accessed on 5 May 2021].

10. Bouvard V, Baan R, Straif K, et al. A review of human carcinogens-Part B: biological agents. Lancet Oncol 2009;10:321-2. DOI PubMed

11. Sérée O, Altieri M, Guillaume E, et al. Longterm risk of solid organ de novo malignancies after liver transplantation: a French national study on 11,226 Patients. Liver Transpl 2018;24:1425-36. DOI PubMed

12. Aberg F, Pukkala E, Höckerstedt K, Sankila R, Isoniemi H. Risk of malignant neoplasms after liver transplantation: a population-based study. Liver Transpl 2008;14:1428-36. DOI PubMed

13. Haagsma EB, Hagens VE, Schaapveld M, et al. Increased cancer risk after liver transplantation: a population-based study. J Hepatol 2001;34:84-91. DOI PubMed

14. Nordin A, Åberg F, Pukkala E, et al. Decreasing incidence of cancer after liver transplantation-a Nordic population-based study over 3 decades. Am J Transplant 2018;18:952-63. DOI PubMed

15. Jiang Y, Villeneuve PJ, Fenton SS, Schaubel DE, Lilly L, Mao Y. Liver transplantation and subsequent risk of cancer: findings from a Canadian cohort study. Liver Transpl 2008;14:1588-97. DOI PubMed

16. Collett D, Mumford L, Banner NR, Neuberger J, Watson C. Comparison of the incidence of malignancy in recipients of different types of organ: a UK Registry audit. Am J Transplant 2010;10:1889-96. DOI PubMed

17. Krynitz B, Edgren G, Lindelöf B, et al. Risk of skin cancer and other malignancies in kidney, liver, heart and lung transplant recipients 1970 to 2008--a Swedish population-based study. Int J Cancer 2013;132:1429-38. DOI PubMed

18. Taborelli M, Piselli P, Ettorre GM, et al; Italian Transplant \& Cancer Cohort Study. Risk of virus and non-virus related malignancies following immunosuppression in a cohort of liver transplant recipients. Italy, 1985-2014. Int J Cancer 2018;143:1588-94. DOI PubMed

19. van Leeuwen MT, Grulich AE, Webster AC, et al. Immunosuppression and other risk factors for early and late non-Hodgkin lymphoma after kidney transplantation. Blood 2009;114:630-7. DOI PubMed

20. Schrem H, Kurok M, Kaltenborn A, et al. Incidence and long-term risk of de novo malignancies after liver transplantation with implications for prevention and detection. Liver Transpl 2013;19:1252-61. DOI PubMed

21. Rompianesi G, Ravikumar R, Jose S, et al. Incidence and outcome of colorectal cancer in liver transplant recipients: a national, multicentre analysis on 8115 patients. Liver Int 2019;39:353-60. DOI PubMed

22. Safaeian M, Robbins HA, Berndt SI, Lynch CF, Fraumeni JF Jr, Engels EA. Risk of colorectal cancer after solid organ transplantation in the United States. Am J Transplant 2016;16:960-7. DOI PubMed PMC

23. D'Arcy ME, Castenson D, Lynch CF, et al. Risk of rare cancers among solid organ transplant recipients. J Natl Cancer Inst 2021;113:199-207. DOI PubMed PMC

24. Lee KF, Tsai YT, Lin CY, et al. Cancer Incidence among heart, kidney, and liver transplant recipients in Taiwan. PLoS One 2016;11:e155602. DOI PubMed PMC

25. Park B, Yoon J, Choi D, et al. De novo cancer incidence after kidney and liver transplantation: Results from a nationwide population based data. Sci Rep 2019;9:17202. DOI PubMed PMC

26. Tsai HI, Lee CW, Kuo CF, et al. De novo malignancy in organ transplant recipients in Taiwan: a nationwide cohort population study. Oncotarget 2017;8:36685-95. DOI PubMed PMC

27. Heo J, Noh OK, Oh YT, Chun M, Kim L. Second primary cancer after liver transplantation in hepatocellular carcinoma: a nationwide population-based study. Hepatol Int 2017;11:523-8. DOI PubMed

28. Bhat M, Mara K, Dierkhising R, Watt KD. Gender, Race and disease etiology predict de novo malignancy risk after liver transplantation: insights for future individualized cancer screening guidance. Transplantation 2019;103:91-100. DOI PubMed

29. Rademacher S, Seehofer D, Eurich D, et al. The 28-year incidence of de novo malignancies after liver transplantation: a single-center analysis of risk factors and mortality in 1616 patients. Liver Transpl 2017;23:1404-14. DOI PubMed 
30. Wimmer CD, Angele MK, Schwarz B, et al. Impact of cyclosporine versus tacrolimus on the incidence of de novo malignancy following liver transplantation: a single center experience with 609 patients. Transpl Int 2013;26:999-1006. DOI PubMed

31. Noone AM, Pfeiffer RM, Dorgan JF, et al. Cancer-attributable mortality among solid organ transplant recipients in the United States: 1987 through 2014. Cancer 2019;125:2647-55. DOI PubMed PMC

32. Watt KD, Pedersen RA, Kremers WK, Heimbach JK, Charlton MR. Evolution of causes and risk factors for mortality post-liver transplant: results of the NIDDK long-term follow-up study. Am J Transplant 2010;10:1420-7. DOI PubMed PMC

33. Na R, Grulich AE, Meagher NS, McCaughan GW, Keogh AM, Vajdic CM. De novo cancer-related death in Australian liver and cardiothoracic transplant recipients. Am J Transplant 2013;13:1296-304. DOI PubMed

34. Acuna SA, Fernandes KA, Daly C, et al. Cancer mortality among recipients of solid-organ transplantation in Ontario, Canada. JAMA Oncol 2016;2:463-9. DOI PubMed

35. D'Arcy ME, Coghill AE, Lynch CF, et al. Survival after a cancer diagnosis among solid organ transplant recipients in the United States. Cancer 2019;125:933-42. DOI PubMed PMC

36. Miao Y, Everly JJ, Gross TG, et al. De novo cancers arising in organ transplant recipients are associated with adverse outcomes compared with the general population. Transplantation 2009;87:1347-59. DOI PubMed

37. Vajdic CM, Chong AH, Kelly PJ, et al. Survival after cutaneous melanoma in kidney transplant recipients: a population-based matched cohort study. Am J Transplant 2014;14:1368-75. DOI PubMed

38. Benoni H, Eloranta S, Ekbom A, Wilczek H, Smedby KE. Survival among solid organ transplant recipients diagnosed with cancer compared to nontransplanted cancer patients-a nationwide study. Int J Cancer 2020;146:682-91. DOI PubMed

39. Younossi ZM, Stepanova M, Saab S, et al. The impact of viral hepatitis-related hepatocellular carcinoma to post-transplant outcomes. $J$ Viral Hepat 2016;23:53-61. DOI PubMed

40. Zamoiski RD, Yanik E, Gibson TM, et al. Risk of second malignancies in solid organ transplant recipients who develop keratinocyte cancers. Cancer Res 2017;77:4196-203. DOI PubMed PMC

41. Mangus RS, Fridell JA, Kubal CA, et al. Worse long-term patient survival and higher cancer rates in liver transplant recipients with a history of smoking. Transplantation 2015;99:1862-8. DOI PubMed

42. Herrero JI, Pardo F, D'Avola D, et al. Risk factors of lung, head and neck, esophageal, and kidney and urinary tract carcinomas after liver transplantation: the effect of smoking withdrawal. Liver Transpl 2011;17:402-8. DOI PubMed

43. Desai R, Collett D, Watson CJ, Johnson PJ, Moss P, Neuberger J. Impact of cytomegalovirus on long-term mortality and cancer risk after organ transplantation. Transplantation 2015;99:1989-94. DOI PubMed

44. Leblond V, Davi F, Charlotte F, et al. Posttransplant lymphoproliferative disorders not associated with Epstein-Barr virus: a distinct entity? J Clin Oncol 1998;16:2052-9. DOI PubMed PMC

45. Dotti G, Fiocchi R, Motta T, et al. Epstein-Barr virus-negative lymphoproliferate disorders in long-term survivors after heart, kidney, and liver transplant. Transplantation 2000;69:827-33. DOI PubMed

46. Yanik EL, Smith JM, Shiels MS, et al. Cancer Risk After Pediatric Solid Organ Transplantation. Pediatrics 2017;139:e20163893. DOI PubMed PMC

47. Piselli P, Burra P, Lauro A, et al; Italian Transplant and Cancer Cohort Study. Head and neck and esophageal cancers after liver transplant: results from a multicenter cohort study. Italy, 1997-2010. Transpl Int 2015;28:841-8. DOI PubMed

48. Krynitz B, Olsson H, Lundh Rozell B, Lindelöf B, Edgren G, Smedby KE. Risk of basal cell carcinoma in Swedish organ transplant recipients: a population-based study. Br J Dermatol 2016;174:95-103. DOI PubMed

49. Park CK, Fung K, Austin PC, et al. Incidence and risk factors of keratinocyte carcinoma after first solid organ transplant in Ontario, Canada. JAMA Dermatol;2019:1041. DOI PubMed PMC

50. Harwood CA, Mesher D, McGregor JM, et al. A surveillance model for skin cancer in organ transplant recipients: a 22-year prospective study in an ethnically diverse population. Am J Transplant 2013;13:119-29. DOI PubMed

51. Ducroux E, Boillot O, Ocampo MA, et al. Skin cancers after liver transplantation: retrospective single-center study on 371 recipients. Transplantation 2014;98:335-40. DOI PubMed

52. Kim YJ, Jung CJ, Park GH, et al. Twenty-eight-year incidence and characteristics of post-transplant skin cancers: Comparative analysis of past and recent 10-year experience. J Dermatol 2020;47:1131-40. DOI PubMed

53. Funk-Debleds P, Ducroux E, Guillaud O, et al. Subsequent nonmelanoma skin cancers and impact of immunosuppression in liver transplant recipients. J Am Acad Dermatol 2018;79:84-91. DOI PubMed

54. Murray SL, Daly FE, O'Kelly P, et al. The impact of switching to mTOR inhibitor-based immunosuppression on long-term nonmelanoma skin cancer incidence and renal function in kidney and liver transplant recipients. Ren Fail 2020;42:607-12. DOI PubMed PMC

55. Phan K, Moloney FJ, Hogarty DT, Lenane P, McColl D, Yazdabadi A. Mammalian target of rapamycin (mTOR) inhibitors and skin cancer risk in nonrenal solid organ transplant recipients: systematic review and meta-analysis. Int J Dermatol ;2019:91-8. DOI PubMed

56. Knoll GA, Kokolo MB, Mallick R, et al. Effect of sirolimus on malignancy and survival after kidney transplantation: systematic review and meta-analysis of individual patient data. BMJ 2014;349:g6679. DOI PubMed PMC

57. Yanik EL, Chinnakotla S, Gustafson SK, et al. Effects of maintenance immunosuppression with sirolimus after liver transplant for hepatocellular carcinoma. Liver Transpl 2016;22:627-34. DOI PubMed PMC

58. Eccher A, Girolami I, Marletta S, et al. Donor-transmitted cancers in transplanted livers: analysis of clinical outcomes. Liver Transpl 2021;27:55-66. DOI PubMed

59. Roemhild A, Otto NM, Moll G, et al. Regulatory T cells for minimising immune suppression in kidney transplantation: phase I/IIa 
clinical trial. BMJ 2020;371:m3734. DOI PubMed PMC

60. Clavien P, Muller X, de Oliveira ML, Dutkowski P, Sanchez-fueyo A. Can immunosuppression be stopped after liver transplantation? Lancet Gastroenterol Hepatol 2017;2:531-7. DOI PubMed

61. Moscicki AB, Flowers L, Huchko MJ, et al. Guidelines for cervical cancer screening in immunosuppressed women without HIV infection. J Low Genit Tract Dis 2019;23:87-101. DOI PubMed

62. Krynitz B, Rozell BL, Lyth J, Smedby KE, Lindelöf B. Cutaneous malignant melanoma in the Swedish organ transplantation cohort: a study of clinicopathological characteristics and mortality. J Am Acad Dermatol 2015;73:106-113.e2. DOI PubMed

63. Maor D, Vajdic CM, Cumming S, et al. Melanoma in a cohort of organ transplant recipients: experience from a dedicated transplant dermatology clinic in Victoria, Australia. J Am Acad Dermatol 2020;83:773-9. DOI PubMed

64. Chan AW, Fung K, Austin PC, et al. Improved keratinocyte carcinoma outcomes with annual dermatology assessment after solid organ transplantation: Population-based cohort study. Am J Transplant 2019;19:522-31. DOI PubMed

65. Stapleton CP, Birdwell KA, McKnight AJ, et al. Polygenic risk score as a determinant of risk of non-melanoma skin cancer in a European-descent renal transplant cohort. Am J Transplant 2019;19:801-10. DOI PubMed PMC

66. Stapleton CP, Chang BL, Keating BJ, Conlon PJ, Cavalleri GL. Polygenic risk score of non-melanoma skin cancer predicts posttransplant skin cancer across multiple organ types. Clin Transplant 2020;34:e13904. DOI PubMed

67. de Koning HJ, van der Aalst CM, de Jong PA, et al. Reduced lung-cancer mortality with volume CT screening in a randomized trial. $N$ Engl J Med 2020;382:503-13. DOI PubMed

68. Aberle DR, Adams AM, Berg CD, et al; National Lung Screening Trial Research Team. Reduced lung-cancer mortality with low-dose computed tomographic screening. N Engl J Med 2011;365:395-409. DOI PubMed PMC

69. Renaud L, Hilleret MN, Thimonier E, et al. De novo malignancies screening after liver transplantation for alcoholic liver disease: a comparative opportunistic study. Liver Transpl 2018;24:1690-8. DOI PubMed

70. Gong CS, Yoo MW, Kim BS, et al. De novo gastric cancer after liver transplantation. Ann Transplant 2016;21:386-91. DOI PubMed

71. Miura K, Way M, Jiyad Z, et al. Omega-3 fatty acid intake and decreased risk of skin cancer in organ transplant recipients. Eur J Nutr 2020. DOI PubMed

72. Jamieson NJ, Hanson CS, Josephson MA, et al. Motivations, challenges, and attitudes to self-management in kidney transplant recipients: a systematic review of qualitative studies. Am J Kidney Dis 2016;67:461-78. DOI PubMed

73. Donovan JC, Shaw JC. Compliance with sun protection following organ transplantation. Arch Dermatol 2006;142:1232-3. DOI PubMed

74. Watt KD. Keys to long-term care of the liver transplant recipient. Nat Rev Gastroenterol Hepatol 2015;12:639-48. DOI PubMed

75. Harwood CA, Leedham-Green M, Leigh IM, Proby CM. Low-dose retinoids in the prevention of cutaneous squamous cell carcinomas in organ transplant recipients: a 16-year retrospective study. Arch Dermatol 2005;141:456-64. DOI PubMed 